Review began 11/27/2021 Review ended 12/31/2021 Published 01/04/2022

๑) Copyright 2022

Sahu et al. This is an open access article distributed under the terms of the Creative Commons Attribution License CC-BY 4.0., which permits unrestricted use, distribution, and reproduction in any medium, provided the original author and source are credited.

\section{High Myopia: A Pointer of an Inborn Error of Metabolism}

Sanjay Kumar Sahu ${ }^{1}$, Jyoti Ranjan Behera ${ }^{1}$, Jishnu KR ${ }^{1}$, Moparthi Puramjai ${ }^{1}$, Ramakrushna Gudu ${ }^{1}$, Arun K. Dash ${ }^{1}$, Amit R. Rup ${ }^{1}$, Sibabratta Patnaik ${ }^{1}$

1. Pediatrics, Kalinga Institute of Medical Sciences, Bhubaneswar, IND

Corresponding author: Jyoti Ranjan Behera, dr.jyoti2011@gmail.com

\title{
Abstract
}

An 11-year-old boy with marfanoid habitus and high myopia presented with multiple episodes of seizures. He was found to have arachnodactyly, hypermobile joints, ectopia lentis, cerebral venous sinus thrombosis (CVST) with very high serum methionine and homocysteine. Genetic evaluation unveiled homocystinuria due to cystathionine beta-synthase deficiency. The patient was treated with high-dose pyridoxine, methionine restricted diet, anticonvulsants, warfarin, and correction of ectopia lentis. Homocystinuria should be suspected in patients with tall stature and pathological myopia. Early treatment can prevent thromboembolic complications.

Categories: Genetics, Ophthalmology, Pediatrics

Keywords: cerebral sinovenous thrombosis, cystathionine beta synthase, homocystinuria, pyridoxine, csvt, ectopia lentis

\section{Introduction}

Homocystinuria is an inborn error of methionine metabolism due to deficiency of cystathionine- $\beta$-synthase (CBS) with an incidence of one in 200,000 to one in 350,000 live births and an even higher incidence of one in 800 live births is seen in some countries like Qatar [1]. It is inherited as an autosomal recessive trait. The spectrum of manifestations varies from being asymptomatic to severe multisystem involvement. The chief presenting features are ectopia lentis, marfanoid habitus, progressive intellectual disability, and thromboembolic phenomena [2]. We present the case of an 11-year-old boy presenting with high myopia and seizures diagnosed to have classic homocystinuria.

\section{Case Presentation}

An 11-year-old-boy presented to the emergency department with multiple episodes of generalized seizures for one day with no history of fever, vomiting, altered sensorium, or focal neurological deficit. He was having high myopia of - 22D and poor scholastic performance. There was no past history or family history of seizure. He was born out of non-consanguineous marriage with a birth weight of $3.2 \mathrm{~kg}$ and an uneventful perinatal period. There was no history of sibling death or abortion. Anthropometry revealed a height of 165 $\mathrm{cm}$, which was greater than +2 SD for his age, suggestive of tall stature. On examination, the child was having marfanoid habitus with hypermobility of joints and arachnodactyly (Figure 1). There were no neurocutaneous markers. Cardiac and other systemic examinations were normal. 


\section{Cureus}

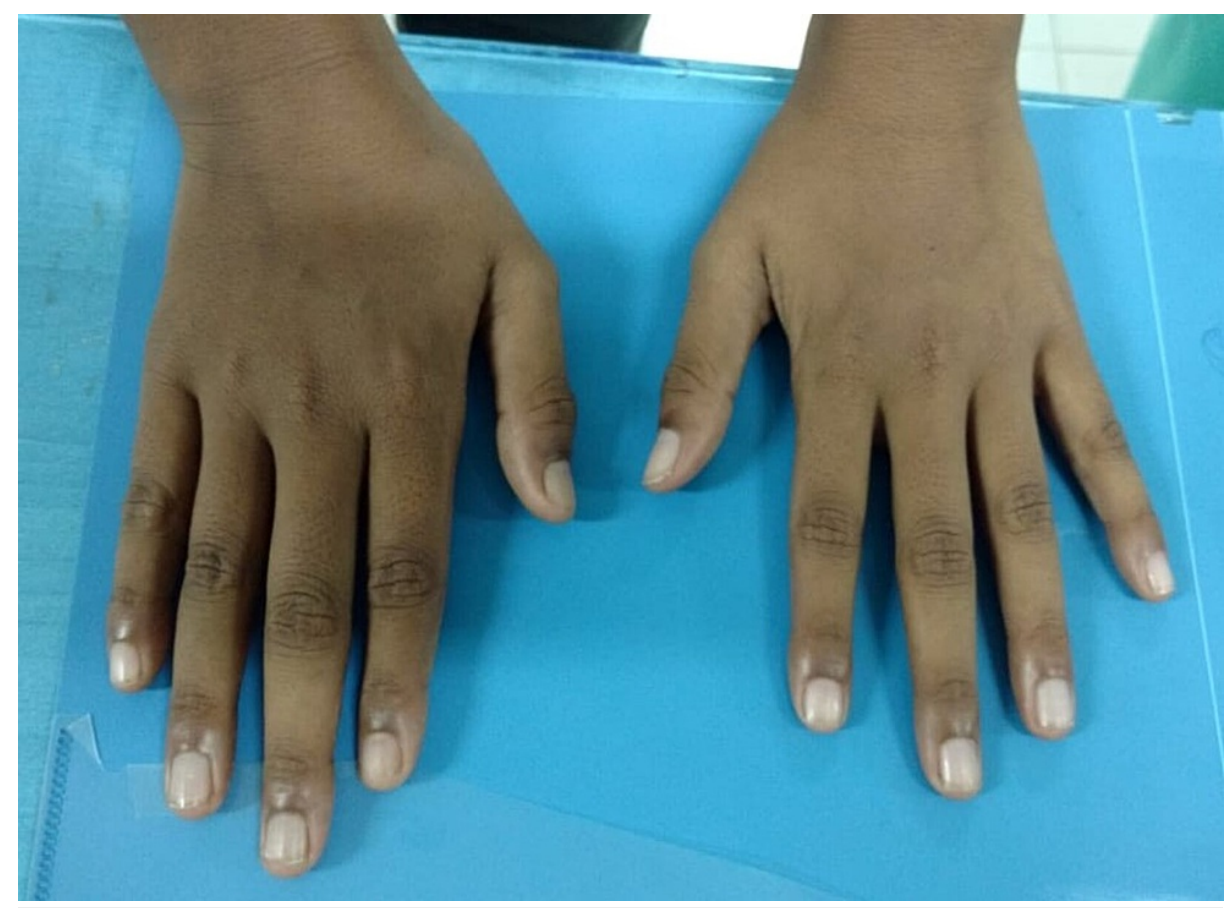

FIGURE 1: Arachnodactyly (Long, slender and curved fingers)

On investigation, complete blood counts revealed hemoglobin $12 \mathrm{gm} / \mathrm{dl}$, total leucocyte count 7800/cu $\mathrm{mm}$ and total platelet count 4 lacs /cu mm. C- reactive protein was $2 \mathrm{mg} / \mathrm{L}$, serum sodium $139 \mathrm{mmol} / \mathrm{L}$, serum potassium $4.4 \mathrm{mmol} / \mathrm{L}$, and serum calcium was $9 \mathrm{mg} / \mathrm{dL}$. Ophthalmological examination was done in view of high myopia and revealed ectopia lentis in both eyes (Figure 2). Contrast-enhanced computed tomography (CECT) brain revealed cerebral venous sinus thrombosis (CVST) (Figure 3).

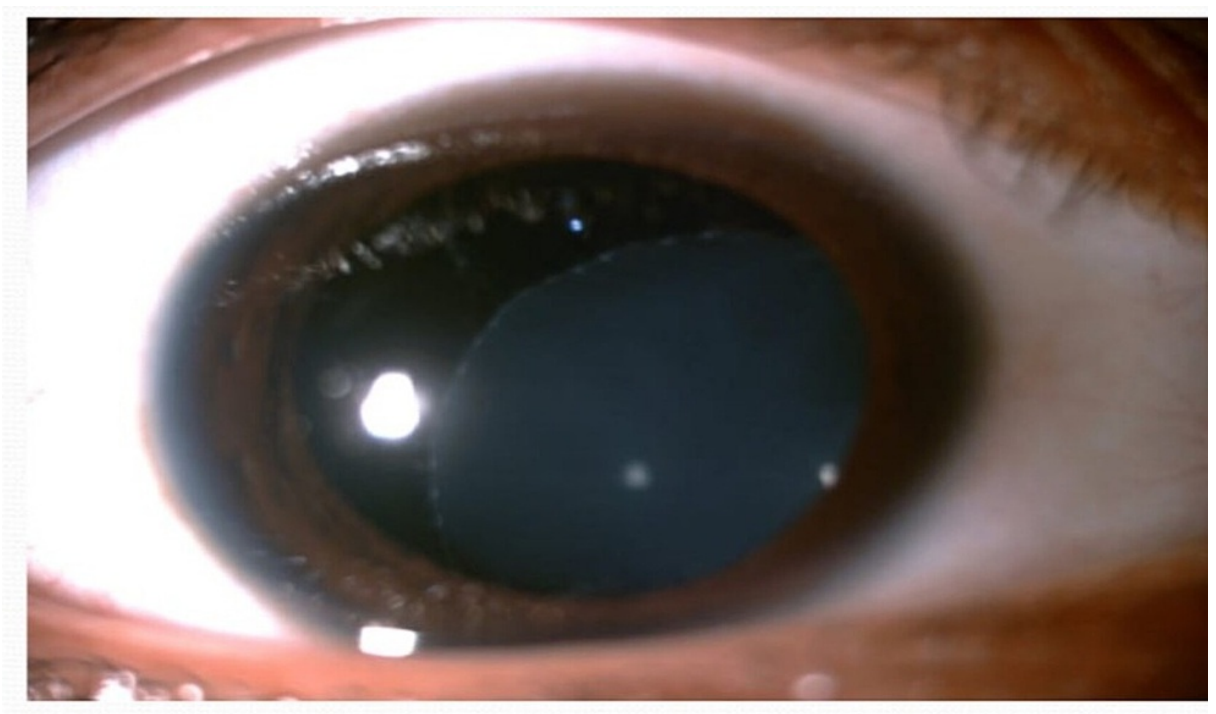

FIGURE 2: Inferonasal displacement of lens (ectopia lentis) of right eye. Similar finding was also present in left eye. 


\section{Cureus}

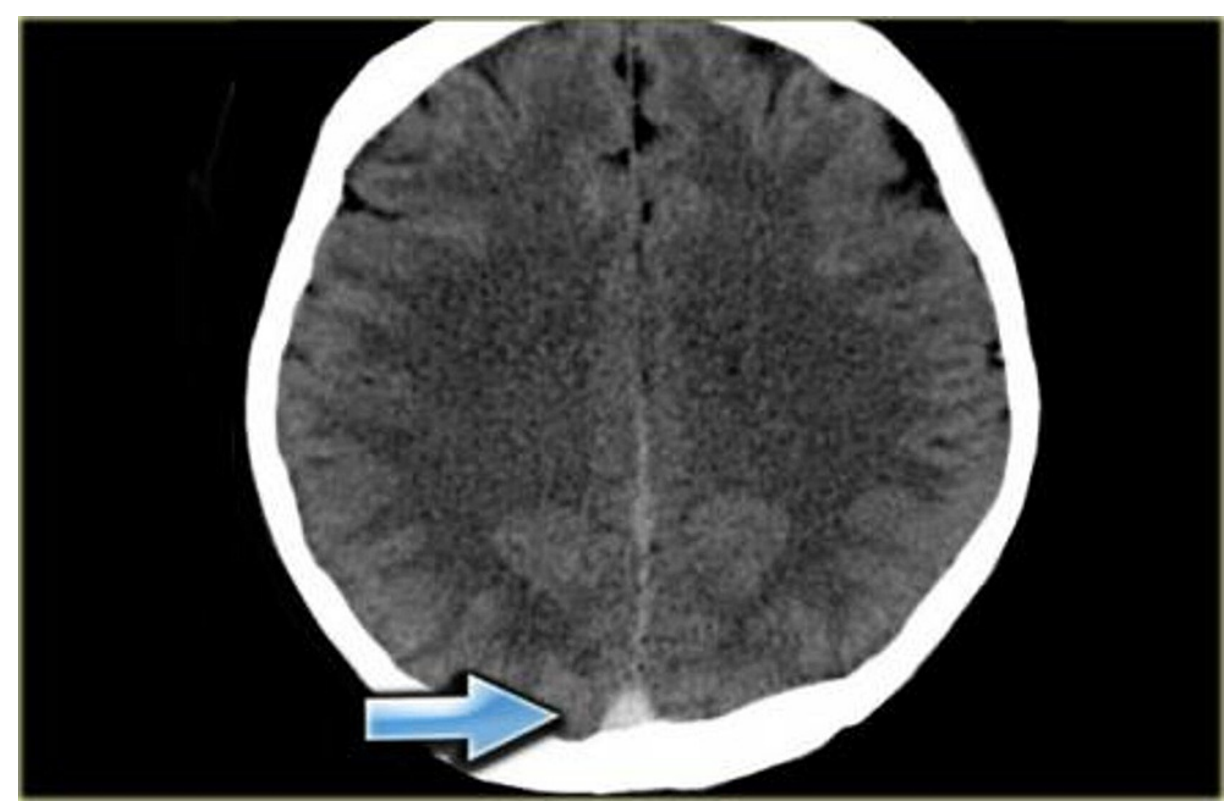

\section{FIGURE 3: CECT brain showing CVST (arrowhead)}

CECT: contrast-enhanced computed tomography; CVST: cerebral venous sinus thrombosis

Homocystinuria, Marfan syndrome, and prothrombotic disorders (protein C deficiency, protein S deficiency, and antithrombin III deficiency) were considered as the differentials. On further workup, the coagulation profile was normal (PT-11.6 secs, INR - 0.9, aPTT - 26 secs). Protein C, protein S, and antithrombin III levels were within the normal limit. Echocardiography revealed no abnormality. Both serum and urinary homocysteine and methionine level were elevated. Genetic evaluation unveiled CBS deficiency confirming the diagnosis of homocystinuria. He was advised a methionine-restricted diet, a high dose of pyridoxine, and folic acid. For control of seizures, anticonvulsant was started. Low molecular weight heparin was given for CVST. Ectopia lentis was corrected surgically following which myopia dramatically improved to -10D. The child was discharged on warfarin for CVST.

\begin{tabular}{|c|c|c|}
\hline Parameters & Observed value & Reference range \\
\hline Hemoglobin & $12 \mathrm{gm} / \mathrm{dl}$ & $11.1-14.1 \mathrm{gm} / \mathrm{dl}$ \\
\hline Total Leucocyte count & $7.8 \times 10^{3 / / \mathrm{LL}}$ & $5-15 \times 10^{3 / \mu L}$ \\
\hline Total RBC count & $4.2 \times 10^{6} / \mu \mathrm{L}$ & $3.9-5.1 \times 10^{6 / \mu \mathrm{L}}$ \\
\hline Total Platelet count & $400 \times 10^{3} / \mu \mathrm{L}$ & $200-550 \times 10^{3 / \mu L}$ \\
\hline C Reactive Protein & $2 \mathrm{mg} / \mathrm{L}$ & $<5 \mathrm{mg} / \mathrm{L}$ \\
\hline Serum sodium & $139 \mathrm{mmol/L}$ & $138-145 \mathrm{mmol} / \mathrm{L}$ \\
\hline Serum potassium & $4.4 \mathrm{mmol} / \mathrm{L}$ & $3.4-4.7 \mathrm{mmo} / \mathrm{L}$ \\
\hline Serum calcium & $9 \mathrm{mg} / \mathrm{dL}$ & 8.5 - $10.5 \mathrm{mg} / \mathrm{dL}$ \\
\hline Prothrombin time & $11.6 \mathrm{sec}$ & $10-15$ secs \\
\hline Activated partial thromboplastin time & $26 \mathrm{sec}$ & $25-36$ secs \\
\hline
\end{tabular}

TABLE 1: Value of various laboratory parameters

On the six-month follow-up, the child was seizure-free without any thrombotic episode. Both plasma and urine homocysteine and methionine levels had decreased. He was also on regular ophthalmological followup. After two years of diagnosis, he was off anticonvulsant; however, scholastic performance continues to be poor. 


\section{Discussion}

The distinctive features of homocystinuria are marfanoid habitus, ectopia lentis, intellectual disability, thromboembolic phenomena, and osteoporosis [2]. Regardless of age and typical clinical features, homocystinuria should be considered in the differential diagnosis of thrombotic episodes [3]. As ectopia lentis is the hallmark and the most consistent feature, finding a dislocated lens should always raise suspicion of homocystinuria [4]. It is also found in conditions like Ehlers Danlos syndrome, Weill Marchesani syndrome, and sulfite oxidase deficiency.

Based on clinical manifestations and biochemical findings, homocystinuria is classified into three types. Type 1 is associated with hypermethioninemia in addition to homocystinuria, which is also termed as classical variety and usually presents after three years of age. Type 2 presents early with feeding difficulty, vomiting, lethargy, hypotonia, and developmental delay with hypomethioninemia and megaloblastic anemia. Type 3 can present during the neonatal period or with chronic manifestations at a later age. Similar to type 2 , these patients have hypomethioninemia but an absence of megaloblastic anemia is the differentiating feature [5].

The main aim of the treatment is to lower the plasma homocysteine level by strategies like high dose pyridoxine, folic acid, and dietary restriction of methionine along with treatment of complications like ectopia lentis and thromboembolic episodes, if present. Recent researches revealed that with plasma total homocysteine concentration below $100 \mu \mathrm{mol} / \mathrm{L}$, the occurrence of thromboembolic episodes is less likely. The dose of pyridoxine is $10 \mathrm{mg} / \mathrm{kg} /$ day with $500 \mathrm{mg} /$ day being the maximum dose to continue for lifelong. Adequate folate should be supplemented to all cases with monitoring of vitamin B12 [6].

For those who cannot achieve target levels of homocysteine by pyridoxine and dietary modification, betaine should be considered as an adjunctive. It decreases homocysteine content by converting homocysteine to methionine with the donation of a methyl group. To start, the dose is $100 \mathrm{mg} / \mathrm{kg} /$ day in two divided doses and then titrated according to response (weekly increased by $50 \mathrm{mg} / \mathrm{kg}$ ) [6]. The maximum licensed dose is 3 grams twice daily. In all patients with CBS deficiency, total homocysteine, plasma methionine, vitamin B12, and folate should be monitored frequently. Development of new complications can be prevented by longterm treatment and with good biochemical control but it does not reverse complications those already present. Currently, newborn screening is available for homocystinuria. However, homocystinuria is not a part of routine newborn screening in India (from where the case is reported) till now and it was also not available at the time of the birth of the child. It can be diagnosed from enzyme deficiency in the extract of cells from cultured amniotic fluid and early treatment can be initiated to prevent complications [7]. As the chances of recurrence in subsequent pregnancies increase, a prenatal diagnosis should be done in all subsequent pregnancies of women who already have an affected child [7].

\section{Conclusions}

Homocystinuria is an inborn error of methionine metabolism with many life-threatening adverse outcomes, including intellectual disability and visual impairment. Hence, the entity should be suspected in all children with high myopia, lens dislocation, marfanoid habitus, or thromboembolism. In newborns, screening for inborn errors of metabolism should include early detection of homocystinuria. Timely diagnosis is vital for preventing visual and intellectual disability and also prevents the birth of another affected child. This may improve the quality of life of the patient and ultimately helps in decreasing the disease burden of society.

\section{Additional Information \\ Disclosures}

Human subjects: Consent was obtained or waived by all participants in this study. Conflicts of interest: In compliance with the ICMJE uniform disclosure form, all authors declare the following: Payment/services info: All authors have declared that no financial support was received from any organization for the submitted work. Financial relationships: All authors have declared that they have no financial relationships at present or within the previous three years with any organizations that might have an interest in the submitted work. Other relationships: All authors have declared that there are no other relationships or activities that could appear to have influenced the submitted work.

\section{References}

1. Zschocke J, Kebbewar M, Gan-Schreier H, et al.: Molecular neonatal screening for homocystinuria in the Qatari population. Hum Mutat. 2009, 30:1021-2. 10.1002/humu.20994

2. Mudd SH, Skovby F, Levy HL, et al.: The natural history of homocystinuria due to cystathionine betasynthase deficiency. Am J Hum Genet. 1985, 37:1-31.

3. Hedlund GL: Cerebral sinovenous thrombosis in pediatric practice. Pediatr Radiol. 2013, 43:173-88. 10.1007/s00247-012-2486-Z

4. Burke JP, O'Keefe M, Bowell R, Naughten ER: Ocular complications in homocystinuria--early and late treated. Br J Ophthalmol. 1989, 73:427-31. 10.1136/bjo.73.6.427

5. Mudd SH, Levy HL, Skovby F: Disorders of transsulfuration. The Metabolic Basis of Inherited Disease, 6th edition. Scriver CR, Beaudet AL, Sly WS, Waiie D (ed): McGraw-Hill, Health Professions Division, New York; 


\section{Cureus}

1989. 693-734.

6. Morris AA, Kožich V, Santra S, et al.: Guidelines for the diagnosis and management of cystathionine betasynthase deficiency. J Inherit Metab Dis. 2017, 40:49-74. 10.1007/s10545-016-9979-0

7. Fowler B, Børresen AL, Boman N: Prenatal diagnosis of homocystinuria. Lancet. 1982, 2:875. 10.1016/s01406736(82) $90835-2$ 